\title{
Human herpesvirus- 6 pneumonitis in a patient with follicular lymphoma following immunochemotherapy with rituximab
}

This article was published in the following Dove Press journal: Infection and Drug Resistance

\author{
Saeko Kuwahara-Ota \\ Yoshiaki Chinen \\ Yoshimi Mizuno \\ Tomoko \\ Takimoto-Shimomura \\ Yayoi Matsumura-Kimoto \\ Kazuna Tanba \\ Taku Tsukamoto \\ Shinsuke Mizutani \\ Yuji Shimura \\ Tsutomu Kobayashi \\ Shigeo Horiike \\ Junya Kuroda
}

Department of Medicine, Division of Hematology and Oncology, Kyoto Prefectural University of Medicine, Kyoto, Japan
Correspondence: Yoshiaki Chinen Department of Medicine, Division of Hematology and Oncology, Kyoto Prefectural University of Medicine, 465 Kajii-cho, Kamigyo-ku, Kyoto 602-8566, Japan

Tel $+8 I 7525 I 5740$

Fax +8I 75 25I 5743

Email y-chinen@koto.kpu-m.ac.jp

\begin{abstract}
Primary infection with human herpesvirus-6 (HHV-6) commonly occurs at an early age in children, most often at 3 years of age, and is associated with childhood diseases, such as exanthema subitum, hepatitis, febrile convulsions, or encephalitis. However, the virus occasionally reactivates from its latent state in immunosuppressed adults, especially posttransplant, resulting in serious disseminated, sometimes life-threatening end-organ complications. Herein, we report a case of a 68-year-old man with relapsed follicular lymphoma who developed HHV-6 pneumonitis. Eighteen months after achieving second complete remission by salvage immunochemotherapy with rituximab, the patient was complicated by pneumonia, with chest computed tomography finding showing disseminated nodular shadows with groundglass opacity in both lungs. While empiric antibiotic and antifungal therapies did not improve the pneumonia, polymerase chain reaction-based viral screening tests on his bronchoalveolar lavage fluid detected the presence of HHV-6 DNA, and ganciclovir treatment quickly resolved the pneumonia, indicating that he suffered from HHV-6 pneumonitis. He had no other HHV-6related end-organ damage, such as encephalitis. This case suggests that, although extremely rare, HHV-6 reactivation should be considered as one of the candidate pathogens for pulmonary complications of uncertain etiology in patients who have been treated with intensive immunosuppressive chemotherapy, even without hematopoietic stem cell transplantation. Furthermore, polymerase chain reaction-based viral screening testing on bronchoalveolar lavage fluid is a powerful diagnostic tool for pneumonitis due to viral reactivation, including HHV-6 reactivation. Keywords: human herpesvirus-6, pneumonitis, viral reactivation, lymphoma
\end{abstract}

\section{Introduction}

Human herpesvirus 6 (HHV-6) is the sixth herpesvirus with a high affinity for CD4positive T lymphocytes. Primary HHV-6 infection usually occurs in infants and is the most common cause of fever-induced seizures in children up to 3 years of age. Meanwhile, acute HHV-6 infection is rare in immunocompetent adults. After primary infection, HHV-6 normally remains latent in lymphocytes and monocytes and persists at low levels in cells and tissues under immunocompetent conditions. However, the virus potentially reactivates when the immune system becomes severely compromised. ${ }^{1,2}$

Recent progress in organ transplantation, especially hematopoietic stem cell transplantation (HSCT), which requires fine-tuning of allogeneic immune coordination, has increased the opportunities for various types of infectious complications by viral reactivation, such as cytomegalovirus (CMV), varicella-zoster virus, or adenoviruses. . $^{3,4}$ HHV-6 reactivation occurs in up to $50 \%$ of patients undergoing allogeneic HSCT and causes a broad spectrum of clinical manifestations, such as fever, rash, encephalitis, 
hepatitis, bone marrow suppression, and so on. ${ }^{3-6}$ It has also been noted that reactivation of HHV-6 is frequently associated with concomitant $\mathrm{CMV}$ reactivation and increases the severity of CMV disease. ${ }^{4,7}$ Although reactivation of HHV-6 has accounted for most opportunistic infections, transmission of HHV-6 from donors has also been reported with $\mathrm{HSCT}^{8}$ In contrast, life-threatening infectious complications by HHV-6 reactivation after chemotherapy alone are extremely rare.

Follicular lymphoma (FL) is the most common disease subtype of indolent non-Hodgkin lymphoma, accounting for about $10 \%-20 \%$ of all lymphomas. Recent advances in immunochemotherapeutics, including anti-CD20 monoclonal antibodies, have markedly improved the long-term outcomes of FL. However, in most cases, disease relapse requires repeated administration of salvage immunochemotherapies. ${ }^{9,10}$ Such long-term treatment often predisposes FL patients toward a severely immunosuppressed state, which causes increased susceptibility to various types of opportunistic infections, including those by bacteria, fungi, and viruses. ${ }^{11-13}$ Herein, we report a case of a patient with relapsed FL who developed HHV-6 pneumonitis during treatment-free remission state following salvage immunochemotherapy, but was never subjected to HSCT.

\section{Case report}

Written informed consent was taken from the patient for the publication of this report and accompanying images. A 66-year-old man was diagnosed as having FL, grade2, Stage $\mathrm{IV}_{\mathrm{B}}$ according to the Ann Arbor disease staging system. ${ }^{14} \mathrm{He}$ had received hormone replacement therapy with $15 \mathrm{mg}$ of hydrocortisone for primary hypogonadism for 11 years before the diagnosis of FL. After the first-line therapy of six cycles of R-CHOP (rituximab, cyclophosphamide, doxorubicin, vincristine, and prednisolone) therapy, he achieved complete response (CR) and was subjected to rituximab maintenance therapy. However, 6 months after achievement of the first CR, the disease relapsed with the emergence of systemic lymph node swelling and skin involvement on his left shoulder, without the evidence of histologic transformation. Salvage therapy with five cycles of CHASER therapy (cyclophosphamide, high-dose cytarabine, dexamethasone, etoposide, and rituximab ${ }^{15}$ ) successfully induced a second CR. Although the consolidative high-dose chemotherapy supported by autologous HSCT with rituximab in vivo purging was initially planned for the relapsed FL in this patient, this attempt was not accomplished due to mobilization failure of hematopoietic stem cells, and the patient was subjected to watchful observation without treatment. The patient developed CMV retinitis 3 months later, and since then, the patient repeatedly developed CMV antigenemia and retinitis, despite appropriate treatment with valacyclovir. Substitution therapy with intravenous immunoglobulins was also administered every 4 weeks for secondary hypogammaglobulinemia to maintain the serum immunoglobulin $\mathrm{G}$ level over $500 \mathrm{mg} / \mathrm{dL}$.

Eighteen months after completion of CHASER therapy, at the age of 68 years, the patient was hospitalized with the chief complaints of pyrexia, cough, and hypoxemia. Upon admission, blood tests revealed a normal leukocyte count of $6.30 \times 10^{9} / \mathrm{L}$ (normal range: $3.30-8.60 \times 10^{9} / \mathrm{L}$ ) comprising $3.83 \times 10^{9} / \mathrm{L}$ neutrophils $\left(1.24-4.61 \times 10^{9} / \mathrm{L}\right), 0.49 \times 10^{9} / \mathrm{L} \mathrm{CD} 4-$ positive T cells $\left(0.37-1.44 \times 10^{9} / \mathrm{L}\right), 2.44 \times 10^{9} / \mathrm{L} \mathrm{CD} 8$-positive T cells $\left(0.26-1.16 \times 10^{9} / \mathrm{L}\right)$, with a $\mathrm{CD} 4: \mathrm{CD} 8$ ratio $=0.2$, and $1.29 \times 10^{9} / \mathrm{L}$ B cells $\left(0.10-0.46 \times 10^{9} / \mathrm{L}\right)$. Mild anemia of 11.2 $\mathrm{g} / \mathrm{dL}(13.7-16.8 \mathrm{~g} / \mathrm{dL})$ and thrombocytopenia of $112.0 \times 10^{9} / \mathrm{L}$ $\left(158-348 \times 10^{9} / \mathrm{L}\right)$ were present. Serological tests revealed elevated C-reactive protein of $14.92 \mathrm{mg} / \mathrm{dL}(0.00-0.30 \mathrm{mg} /$ $\mathrm{dL}$ ), while lactate dehydrogenase (257 IU/L [120-240 IU/L]) and KL-6 $(206 \mathrm{U} / \mathrm{mL}[<500 \mathrm{U} / \mathrm{mL}])$ were within the normal range. Serum immunoglobulin $\mathrm{G}$ level was maintained at 873 $\mathrm{mg} / \mathrm{dL}$ by intravenous immunoglobulins. Serum immunoglobulin A and M levels were $234 \mathrm{mg} / \mathrm{dL}(102-411 \mathrm{mg} / \mathrm{dL})$ and $176 \mathrm{mg} / \mathrm{dL}$ (30-207 mg/dL), respectively. Although the chest X-ray did not show major abnormal shadows (Figure 1), computed tomography (CT) images identified nodular abnormal shadows in both lungs without lymphoma relapse, revealing that the patient was complicated by pulmonary infection (Figure 2A, B). In the absence of positive bacterial/fungal culture tests or positive serological/blood tests for Aspergillus antigen, Candida albicans antigen, Mycoplasma antibody, $\beta$-D-glucan, and CMV-pp65 antigen, the patient

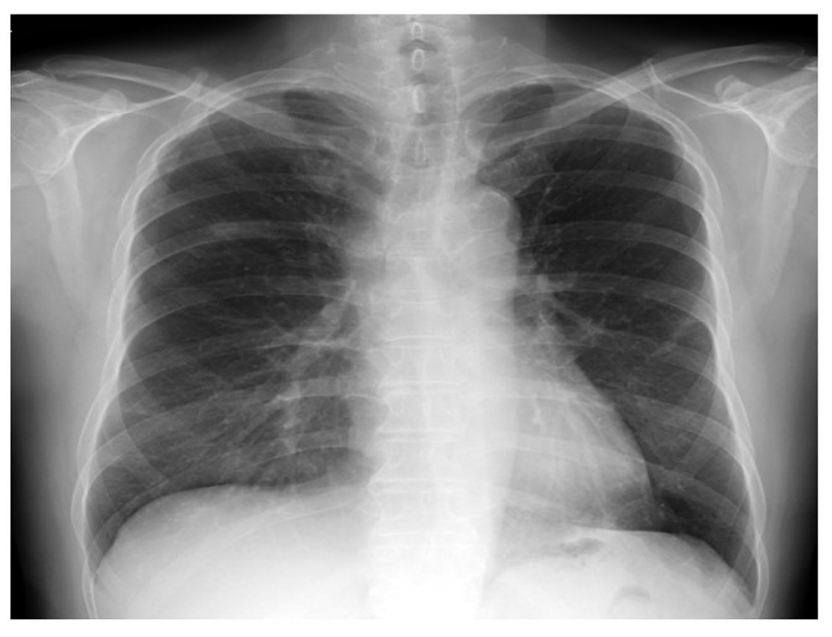

Figure I Chest $X$-ray at the onset of pneumonitis. Note: Chest $\mathrm{X}$-ray did not show major abnormal shadows. 
received empiric antibiotic treatments, including piperacillin/tazobactam, ciprofloxacin, voriconazole, and liposomal amphotericin B. However, the pneumonia got worse, as shown by chest CT images on the 10th day of treatment (Figure 2C, D). Thirteen days after admission, polymerase chain reaction (PCR) tests were performed for herpes simplex virus type 1, herpes simplex virus type 2, varicella-zoster virus, CMV, parvovirus B19, BK virus, John Cunningham virus, Epstein-Barr virus, HHV-6, HHV-7, HHV-8, and hepatitis $B$ virus on a bronchoalveolar lavage (BAL) sample. As the result, only HHV-6 DNA was detected by PCR in the BAL fluid, while HHV-6 DNA was not detected in plasma on the same day as the BAL examination. In addition, no bacterium or fungus was detected as pathogens in the BAL fluid. He was diagnosed as having HHV-6 pneumonitis, and intravenous ganciclovir (GCV; $5 \mathrm{mg} / \mathrm{kg}, \mathrm{q} 12 \mathrm{~h}$ ) therapy was initiated from day14, which quickly resolved the fever and cough within a couple of days and improved the CT findings by day 21 (Figure 2E, F). GCV treatment was changed to oral valganciclovir treatment on day 22 , which was discontinued on day 40 . Since then, no recurrence of HHV-6 pneumonitis has been observed for more than a year. During the course, the patient showed no symptoms of other HHV-6-associated end-organ damage.

\section{Discussion}

HHV-6 pneumonitis is rare, and no standard diagnostic criterion has been established. HHV-6 pneumonitis has been reported to show nonspecific and diverse CT findings: reticulation, ground glass opacity, consolidation, peripheral lung sparing, centrilobular nodules, and pleural effusions. ${ }^{16,17}$ These CT findings are similar to those of Pneumocystis jirovecii pneumonia or CMV pneumonitis, ${ }^{17}$ which makes the differential diagnosis of HHV-6 pneumonitis from other pneumonitis difficult. In addition, it is important to note that chromosomal integration of HHV-6 occurs in about $1 \%$ of the population, and therefore, the detection of HHV-6 DNA does not always indicate reactivation of HHV-6 in such circumstances. However, BAL still plays an important role in the diagnosis of HHV-6 pneumonitis, as was also true with this case. ${ }^{16-19}$ It has also been reported that, when PCR screening for viral pathogen was performed in patients with idiopathic pneumonia syndrome after allogeneic HSCT, HHV-6 was detected as the most frequent pathogen and that the detection
A

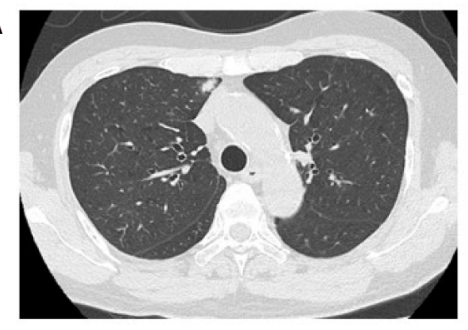

C

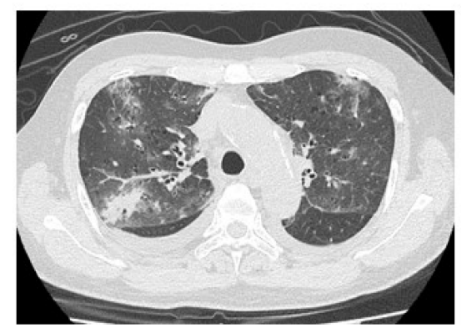

E

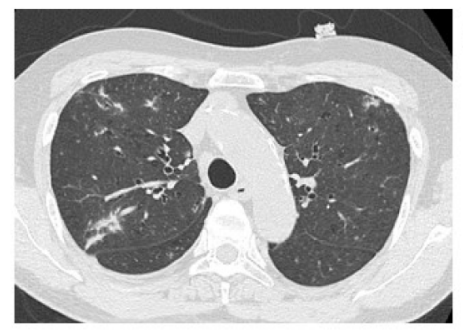

$\mathbf{B}$
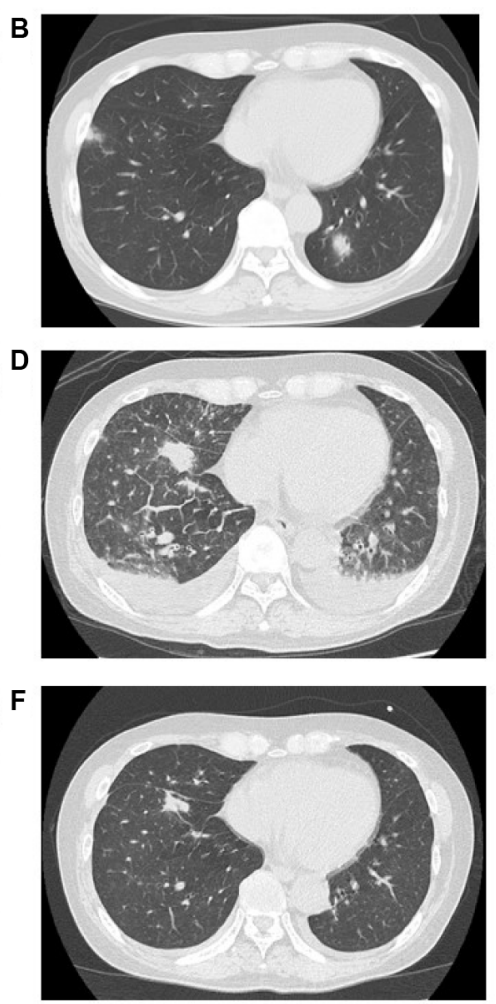

Figure 2 Chest CT images.

Notes: (A) Upper lung field and (B) middle lung filed at the onset of pneumonitis. (C) Upper lung field and (D) middle lung filed on the I0th day of treatment. (E) Upper lung field and (F) middle lung field on the 2 Ist day of treatment. Following start of ganciclovir treatment, bilateral pleural effusions, ground glass opacities, and consolidations have resolved.

Abbreviations: CT, computed tomography. 
of pathogen in BAL samples was associated with increased mortality, regardless of its authenticity as the cause of pneumonitis. ${ }^{4}$ These findings suggest that the detection of HHV-6 DNA in BAL samples could be an appropriate trigger for the initiation of anti-HHV-6 treatment, especially in a severely immunocompromised setting. In addition, a negative test for HHV-6 DNA in plasma suggests no chromosomally integrated $\mathrm{HHV}-6$, further supporting the diagnostic value of positive tests for HHV-6 DNA in BAL sample. Although a standard treatment for HHV-6 pneumonitis has not been established, GCV was effective in our case, as has been reported previously. ${ }^{16-19}$

While immunocompromised patients, especially those who have undergone allogeneic HSCT, are at a high risk of HHV-6 reactivation, ${ }^{3,4,6-8}$ reactivation can also occur in association with intensive chemotherapy, hypogammaglobulinemia, and autologous HSCT..$^{5,9,20,21}$ It is noteworthy that HHV-6 reactivation has been frequently accompanied with the emergence of Pneumocystis jirovecii pneumonia and the reactivation of other viral pathogens, such as CMV or Epstein-Barr virus. ${ }^{21-23}$ Our patient had a sustained immunosuppressive state with hypogammaglobulinemia and a low CD4/CD8 $\mathrm{T}$ cell ratio, with repeated $\mathrm{CMV}$ reactivation that might be caused by continuous steroid replacement therapy for primary hypogonadism and rituximab-containing salvage therapy for relapsed FL. These findings suggest that this case was at a high risk for HHV-6 reactivation and that HHV-6 reactivation should be considered as one of the candidate pathogens for pulmonary complications of uncertain etiology in patients who have been treated with intensive immunosuppressive chemotherapy, even without HSCT.

In conclusion, we report a case of HHV-6 pneumonitis following salvage chemotherapy alone without HSCT for relapsed FL in which PCR testing for HHV-6 DNA in a BAL sample was a useful tool for the diagnosis of HHV-6 pneumonitis.

\section{Disclosure}

The authors report no conflicts of interest in this work.

\section{References}

1. Tesini BL, Epstein LG, Caserta MT. Clinical impact of primary infection with roseoloviruses. Curr Opin Virol. 2014;9:91-96.

2. Zerr DM. Human herpesvirus 6: a clinical update. Herpes. 2006;13(1): 20-24.

3. Inazawa $\mathrm{N}$, Hori $\mathrm{T}$, Hatakeyama $\mathrm{N}$, et al. Large-scale multiplex polymerase chain reaction assay for diagnosis of viral reactivations after allogeneic hematopoietic stem cell transplantation. J Med Virol. 2015;87(8):1427-1435.
4. Seo S, Renaud C, Kuypers JM, et al. Idiopathic pneumonia syndrome after hematopoietic cell transplantation: evidence of occult infectious etiologies. Blood. 2015;125(24):3789-3797.

5. Colombier MA, Amorim S, Salmona M, Thieblemont C, Legoff J, Lafaurie M. HHV-6 reactivation as a cause of fever in autologous hematopoietic stem cell transplant recipients. J Infect. 2017;75(2):155-159.

6. de Pagter PJ, Schuurman R, Meijer E, van Baarle D, Sanders EA, Boelens JJ. Human herpesvirus type 6 reactivation after haematopoietic stem cell transplantation. J Clin Virol. 2008;43(4):361-366.

7. Crocchiolo R, Giordano L, Rimondo A, et al. Human Herpesvirus 6 replication predicts Cytomegalovirus reactivation after allogeneic stem cell transplantation from haploidentical donor. J Clin Virol. 2016;84:24-26.

8. Jeulin H, Salmon A, Gautheret-Dejean A, et al. Contribution of human herpesvirus 6 (HHV-6) viral load in whole blood and serum to investigate integrated HHV-6 transmission after haematopoietic stem cell transplantation. J Clin Virol. 2009;45(1):43-46.

9. Tsukamoto T, Kiyota M, Kawata E, et al. Detection of chromosomal abnormalities by G-banding and prognostic impact in follicular lymphoma in the rituximab era. Int J Hematol. 2017;105(5):658-667.

10. Tsukamoto T, Nakano M, Sato R, et al. High-risk follicular lymphomas harbour more somatic mutations including those in the AID-motif. $S c i$ Rep. 2017;7(1):14039.

11. Gafter-Gvili A, Polliack A. Bendamustine associated immune suppression and infections during therapy of hematological malignancies. Leuk Lymphoma. 2016;57(3):512-519.

12. Aksoy S, Harputluoglu H, Kilickap S, et al. Rituximab-related viral infections in lymphoma patients. Leuk Lymphoma. 2007;48(7):1307-1312.

13. Nordøy T, Husebekk A, Aaberge IS, et al. Humoral immunity to viral and bacterial antigens in lymphoma patients 4-10 years after high-dose therapy with ABMT. Serological responses to revaccinations according to EBMT guidelines. Bone Marrow Transplant. 2001;28(7):681-687.

14. Cheson BD. Staging and response assessment in lymphomas: the new Lugano classification. Chin Clin Oncol. 2015;4(1):5.

15. Oki Y, Ogura M, Kato H, et al. Phase II study of a salvage regimen using cyclophosphamide, high-dose cytarabine, dexamethasone, etoposide, and rituximab in patients with relapsed or refractory B-cell non-Hodgkin's lymphoma. Cancer Sci. 2008;99(1):179-184.

16. Ishio T, Endo T, Okada K, Shigematsu A, Hashino S, Teshima T. Human Herpesvirus- 6 pneumonitis around the engraftment of cord blood transplantation following foscarnet prophylaxis in a patient with acute leukemia. Case Rep Hematol. 2015;2015:949265.

17. Nakayama T, Okada F, Ando Y, et al. A case of pneumonitis and encephalitis associated with human herpesvirus 6 (HHV-6) infection after bone marrow transplantation. Br J Radiol. 2010;83(996):e255-e258.

18. Buchbinder S, Elmaagacli AH, Schaefer UW, Roggendorf M. Human herpesvirus 6 is an important pathogen in infectious lung disease after allogeneic bone marrow transplantation. Bone Marrow Transplant. 2000;26(6): 639-644.

19. Mariotte E, Schnell D, Scieux C, et al. Significance of herpesvirus 6 in BAL fluid of hematology patients with acute respiratory failure. Infection. 2011;39(3):225-230.

20. Frey JW, Cherabie JN, Assi MA. Human herpesvirus-6 encephalitis following chemotherapy induction for acute myelogenous leukemia. Transpl Infect Dis. 2017;19(6).

21. Vuorinen T, Kotilainen P, Lautenschlager I, Kujari H, Krogerus L, Oksi J. Interstitial pneumonitis and coinfection of human herpesvirus 6 and Pneumocystis carinii in a patient with hypogammaglobulinemia. J Clin Microbiol. 2004;42(11):5415-5418.

22. Ogata M, Satou T, Kawano R, et al. High incidence of cytomegalovirus, human herpesvirus-6, and Epstein-Barr virus reactivation in patients receiving cytotoxic chemotherapy for adult $\mathrm{T}$ cell leukemia. J Med Virol. 2011;83(4):702-709.

23. Tormo N, Solano C, de la Cámara R, et al. An assessment of the effect of human herpesvirus-6 replication on active cytomegalovirus infection after allogeneic stem cell transplantation. Biol Blood Marrow Transplant. 2010;16(5):653-661. 
Infection and Drug Resistance is an international, peer-reviewed openaccess journal that focuses on the optimal treatment of infection (bacterial, fungal and viral) and the development and institution of preventive strategies to minimize the development and spread of resistance. The journal is specifically concerned with the epidemiology of antibiotic resistance and the mechanisms of resistance development and diffusion in both hospitals and the community. The manuscript management system is completely online and includes a very quick and fair peerreview system, which is all easy to use. Visit http://www.dovepress.com/ testimonials.php to read real quotes from published authors.

Submit your manuscript here: https://www.dovepress.com/infection-and-drug-resistance-journal 